\title{
Customer Value Measurement Under the Background of E-commerce
}

\author{
Lanchun $\mathrm{Li}^{1}{ }^{1 *}$ \\ ${ }^{1}$ Inner Mongolia University of Finance and Economics, Hohhot, Inner Mongolia, China \\ *Corresponding author. Email: LLC06288@163.com
}

\begin{abstract}
Online shopping has become the mainstream of shopping in recent years. With the rapid development of ecommerce, online shopping has basically entered a mature stage, and the customer base is basically stable. Improvement of the existing customer value has become the key to the development of e-commerce enterprises. This paper discusses how e-commerce enterprises analyze customer value and how to improve customer value from three perspectives. Referring to the data of Alibaba and Amazon, the author uses natural language processing and other methods for data analysis. By analyzing the goods purchased by customers, the consumption level and preference of customers can be inferred. By recommending similar goods on the home page, the customer value can be improved. The amount of time a customer spends on an application is directly proportional to consumption. Emotional interaction can promote consumption. Starting from customer evaluation, we can improve the online shopping platform intuitively and enhance customer value.
\end{abstract}

Keywords: Customer value measure, E-commerce, Business analysis, Enhancing customer value.

\section{INTRODUCTION}

In the new era, online shopping is rising rapidly with the advantage of saving time and effort compared with offline shopping. Online shopping can quickly classify and integrate goods, and provide customers with more and better choices. In addition, online shopping has no time and space constraints, customers can use it anytime and anywhere, thus maximizing customers' demands and saving their time. But online shopping also has a lot of shortcomings that offline shopping will not exist. For example, the time for customers to get goods is extended, customers can not test the real goods, poor network condition may lead to a bad online shopping experience, online shop has excessive publicity, which brings a series of problems such as low consumer satisfaction [1]. The huge difference between traditional shopping and online shopping makes great changes in customer value, which is both an opportunity and a challenge. The business model of online shop can't copy the traditional shopping model. Customer value measurement and customer value prediction also need to establish a new system to calculate. This paper mainly discusses the customer value under the new shopping mode, as well as the new business model and strategy that enterprises should formulate. Enterprises under the new shopping mode should have different concerns, so that enterprises can enhance customer value and long-term profitability.

\section{CUSTOMER VALUE ANALYSIS}

Customer value is the total value that customers can bring to enterprises (including reputation, corporate profits, etc.), including the value that once brought and the value that may be brought in the future. After measuring the value customers have brought to the enterprise, by analyzing the preferences, types and methods of goods customers have purchased, the corresponding marketing strategy can be formulated, thus making customers bring more value to the enterprise in the future. Therefore, customer value measurement is a very favorable way of modern enterprise management. Attracting more customers and enhance customer loyalty is the key to creating future customer value. The most direct way to measure customer value is to analyze the factors of customer loyalty. The factors that affect customer loyalty are: customers' purchase frequency, purchase amount, customers' relationship length, and 
customers' recent trading time. Customers' relationship length is proportional to customers' loyalty [2]. K-means is a good method to calculate customer loyalty. Customers are divided into $\mathrm{K}$ groups. Through multiple clustering and distribution, customers are divided into groups with different loyalty.

Customer value can also be measured from other aspects.

\subsection{Analysis of Historical Purchasing Behavior}

\subsubsection{Customer Purchasing Power}

According to the prices and types of goods that customers have purchased, the purchasing power of customers can be reflected to a certain extent. Based on this, customer value can be calculated. In addition, enterprises should also find out what can be improved from historical data, so as to enhance the value of customers in the future.

By analyzing the customer's purchase behavior, the customer's purchase habits can be understood. For example, the most needed items in a customer's life are often purchased, so the purchase frequency of that item is higher than that of others. For such goods, it is necessary to simplify the procedure of re-purchase. Many consumers have pointed out that the complexity of the purchase procedure is also one of the reasons for them to abandon online purchase. At the end of the 20th century when online shopping had not risen, nearly $70 \%$ of people gave up online shopping because the payment process was too complex. Amazon launched a "one-click purchase" in 1999, greatly simplifying the purchase process. This innovation greatly retained customers, making Amazon rapidly expand its market share in the industry and become the leading brand in the global online shopping platform [1]. Taobao, Alibaba's online shopping platform, has also improved the repurchase process in recent years. Customers can find the goods that need to be ordered again in historical orders, and click "join the shopping cart" directly to make a second purchase, without the need to re-enter the store for the goods.

\subsubsection{Customer Preferences}

By analyzing the purchase history of customers, we can also know the price range of the goods purchased by customers and the style they like. Therefore, we can recommend related products to their personalized front page, which is a good method to actively guide customer consumption. According to many young people, 'unexpected consumption' accounts for a large proportion of consumption with recommended goods. "Unexpected consumption" is not within their purchase plan, but because the items recommended by the platform are seen, and leave the customers with a good impression, or simply because the page is exquisite, the customers purchase without a second thought. The more "unexpected consumption" of customers, the more purchasing power of current customers will increase than that calculated according to historical purchasing records, and the corresponding customer value will increase. Of course, many people also admit that a large part of "unexpected consumption" is impulse consumption. After purchasing, customers may realize that the goods purchased outside the plan are not the goods they really need. When customers feel regret, their dissatisfaction with the shopping platform will also increase. The method of balancing the marketing and customer regret rate is to establish an emotional interaction to transform the impulse consumption into an emotional return. How to establish emotional interaction is the next step for enterprises to consider.

\subsection{Usage Time Analysis}

Shopping has a part of entertainment, and consumer behavior can be roughly divided into two categories, instrumental characteristics and enjoyment characteristics [3]. The consumption activities with instrumental characteristics refer to people's purchase mainly based on the quality and functionality of goods, which is more reflected in offline physical store purchase. The characteristic of enjoyment is that customers want to have fun in the process of shopping. Such customers like to get interactive communication and emotional care in shopping. At this time, the practicality and functionality of goods are no longer the most important thing. Because some goods have no use value for customers, but the customers are willing to pay for it, resulting in "emotional payoff". Young and Feigen put forward this concept in the "grey benefit chain", which is as "Figure 1" shows.

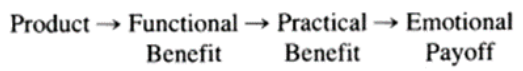

Figure 1 Emotional payoff [2]. 


\subsubsection{The Relationship Between Customers' Time Spent on App and Their Purchasing Power}

According to the data of an online shopping platform, the author calculates the relationship between "time on app" and "yearly amount spend", and concludes that, as "Figure 2" shows, the time customers spend on online shopping software is generally positively correlated with their consumption amount [4].

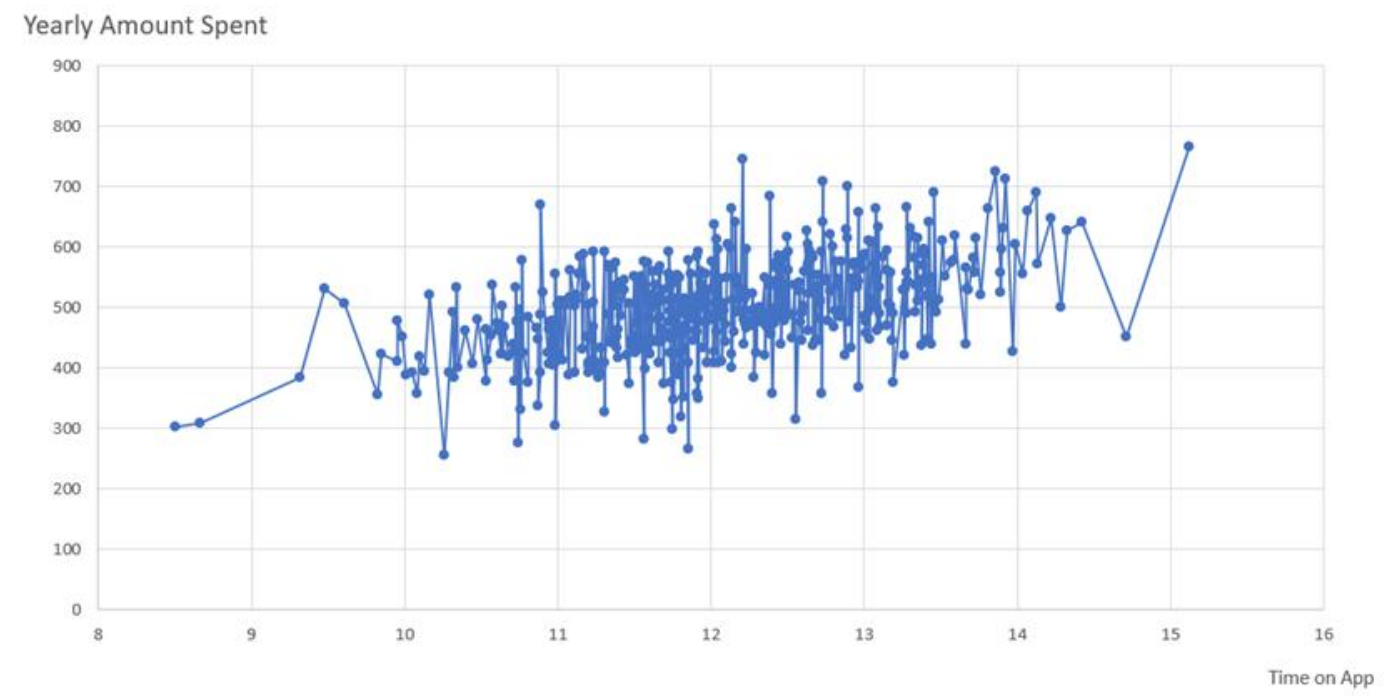

Figure 2 The relationship between customers' time spent on app and their purchasing power.

That is to say, the more time people spend on online shopping software, the greater their propensity to consume. It can also be inferred that people with a greater propensity will spend more time on shopping software, because they need to search for goods, know about the goods, and ask details to the customer service. If the shopping platform can attract customers to spend more time on the shopping software, customers will have the opportunity to buy more goods. The original shopping tendency will be continuously stimulated and the consumption desire will be improved. Such a mechanism is a big reason for "impulsive consumption". If we want to increase the amount of customers' purchase and reduce the probability of regret after "impulsive consumption", the key point is whether we can establish emotional interaction with customers and provide them with an enjoyable shopping experience. This is the difference between impulsive consumption and emotional return.

\subsubsection{The Emotional Connection Between the Platform and Customers}

To provide customers with enjoyment is the key to stand out from competitors in the same industry, and also the key to enhance customer loyalty. Customer experience can bring long-term competitive advantage instead of short-term benefits. The way to achieve it is not brought by a single, small-scale mechanism, but needs a complete service system. The macro aspect (the overall mode of platform operation and the atmosphere in the shopping platform) as well as the micro aspect (the operation mode of each single store in the platform and the details of each purchase process) need to be improved. When customers enjoy the atmosphere and emotional interaction created by a certain shopping platform, they may give their patronage to it again rather than screening on a new one, thus improving the length of customer relationship and turn shortterm customers into long-term ones.

To enhance emotional interaction, in addition to beautifully designed pages and interesting interactive games, the shopping platform can also give consumption other meanings than a commercial transaction. For example, Taobao will draw a certain proportion of the amount from each successful transaction as a public welfare fund to donate to social groups in need. The reason why Alipay's "ants forest" project can quickly gain public attention is also that consumers can get the corresponding points on the ant forest platform by paying water and electricity charges and booking online. The platform 
will help consumers do environmental charity by growing trees in the desert according to these points. Consumers' enthusiasm for environmental protection helps to attract them to use the product for a long time.

In addition, the platform can also establish an emotional connection like friendship with consumers, which is similar to Apple's Siri. When consumers interact with Siri, they will experience the fun of interacting with people. At this time, the mobile phone is more like a friend to consumers than just a mobile phone. Shopping platforms can also personify platforms. Taking Taobao, for instance, the end of the year to the customer in the form of communication between friends, presents a data to show the customer that over the course of using Taobao, how many things consumers bought, how many items they bought, the number of days they used Taobao, etc. Because of the way data appear sweet and interesting, many customers will send the data to show each other with friends on social software. This imperceptibly increases the emotional connection between customers and Taobao, and also makes a good promotion for Taobao. Next time when relatively stable emotional connection, consumers with consumer demand will be more inclined to continue to choose the platform, not on the online platform by comparing the pros and cons of function to decide to choose which platform to spend, because at this time for the consumer that is not only a shopping platform, but old friends.

\subsection{Analysis of Customer Reviews}

The most effective way for enterprises to improve customer satisfaction is to obtain information from reviews, so as to make more targeted improvements. On the basis of natural language pre-processing, enterprises can use the methods of text mining and sentiment analysis [5] to make an overall analysis of all comments, find out the most frequently mentioned aspects by customers, and analyze whether customers' emotions are positive or negative when they mention this aspect. Positive comments can show enterprises the competitive advantage they have now, which is the aspect that needs to be maintained in the future development, while negative comments can point out the areas that they need to improve.

In this article, the author uses Python to analyze 6620 comments of Amazon [6]. After data preprocessing, the author uses natural language processing to count the word frequency, and finally gets the high frequency words in the comments. Apart from prepositions, pronouns and other words without reference, the top nouns have great reference significance. Among them, "time" appeared 2368 times, "delivery" appeared 2273 times, "account" appeared 2238 times. Combined with the original comments, it can be concluded that Amazon still has a lot of potential for improvement in logistics. Most of the dissatisfaction of customers are focused on the speed of logistics and payment process. If Amazon wants to improve customer satisfaction, encourage customers to purchase more, so as to increase customer value, Amazon needs to make great improvements in logistics and payment procedures.

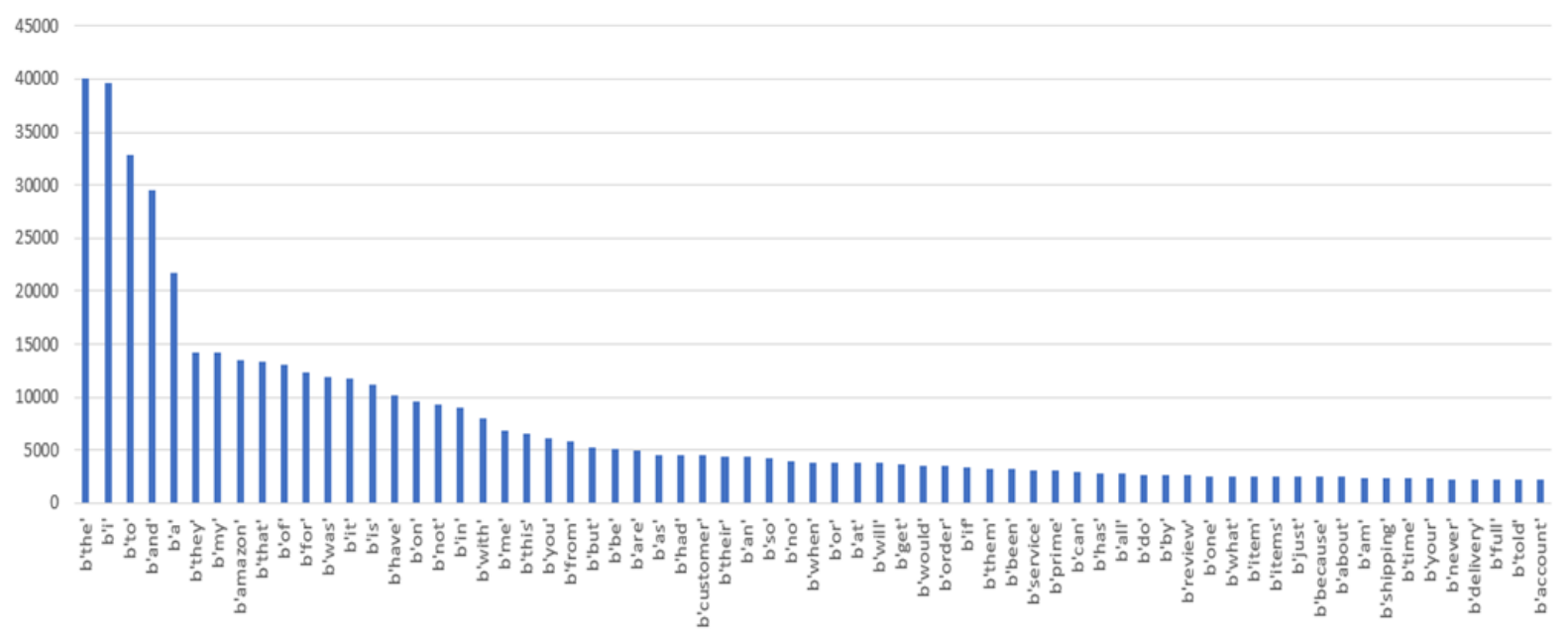

Figure 3 High frequency word calculation results. 
Although customer evaluation is the closest factor to customer consumption demand, it can only be used as a reference, and can never be used as the main basis for formulating business strategy, because customer expectation of products does not represent customer demand. The wife of one of Motorola's engineers complained when she was on vacation about the bad signal of mobile phones in the wild, so several Motorola engineers came up with the idea of allowing signals to cover all corners of the earth, which is the famous "iridium project". As soon as the plan was put forward, it received a lot of people's expectations, and was considered as an unprecedented breakthrough for mobile service. However, after the launch of the service, iridium company invested by Motorola soon declared bankruptcy because of its high price and too few consumers. Therefore, although the concept of modern marketing advocates taking consumers as the center, the evaluation and opinions of consumers still cannot become the "Bible" of enterprise management, and should be considered from the perspective of multi-level marketing [7].

\section{CONCLUSION}

In this paper, customer value can be analyzed from three aspects: historical purchase records of customers, usage time of the customers on the platform and customers' reviews to online shopping platforms. Enterprises can make corresponding strategies according to the results of these three aspects so as to enhance the value that customers can bring to the enterprise. Through the analysis of customers' purchasing history, customers' purchasing power and preferences can be understood, the best recommendation content on the homepage can be provided; Increasing the interaction can enhance the emotional connection between the platform and customers, and emotional connection is also the key to reduce the regret rate after impulse consumption. Making corresponding improvements according to customer's review can better enhance customer loyalty. There are many factors that affect customer value, such as the number of family members, whether married or not, gender, age, education level, social status and so on. Customer value is a pluralistic and comprehensive system. Different goods, different time, different regions will produce different factors that affect customer value. It is difficult for people to determine all the factors that affect customer value. Looking for factors that affect customer value should be carried out for a long time and continuously, because it is difficult for people to think of many influencing factors based on past experience, so people need to explore from more aspects. What needs to be further discussed in the future is what other factors affect customer value and the proportion of each factor in customer value. It is worth mentioning that the analysis of customer value needs to be carried out in multiple dimensions, and the business strategy cannot be made according to only one factor. Such behavior is likely to bring huge losses to the enterprise. The influencing factors mentioned in this paper are relatively few, and only three aspects are discussed, which cannot form a complete and mature customer value analysis model. A mature analysis model still needs more data and algorithms to build, this paper only provides some specific ideas. At present, most enterprises still only focus on the analysis of financial data, and do not spend much energy to analyze customer information. This will make it difficult for the enterprise to make more breakthroughs and improvements after entering the mature stage of development, which is not conducive to the long-term development of the enterprise. In daily operation, enterprises should collect customer information and environmental information as much as possible, issue questionnaires, fill in customer information when members register, and conduct regular market visits, all of which are good ways to collect customer information. It is the key to promote the long-term good development of an enterprise to maximize the customer value while grasping the macroeconomic development of the economic market.

\section{AUTHORS' CONTRIBUTIONS}

\author{
This paper is independently completed by \\ Lanchun Li.
}

\section{ACKNOWLEDGMENTS}

Thanks to the professor's patient instruction, I have a deeper understanding of business analysis and customer value measure. Thank my seniors for helping me operate Python and giving me encouragement. Thanks to my assistant teacher for giving me guidance at all stages of my thesis writing. As well as my thesis tutor, put forward my mistakes in time and help me with my writing. With the help of teachers and classmates, I can finish this paper. I would like to express my heartfelt thanks to them.

\section{REFERENCES}

[1] Satar, Nurhizam Safie Mohd, O. Dastane , and M. Yusnorizam . "Customer Value Proposition for E-Commerce: A Case Study Approach." 
International Journal of Advanced Computer Science and Applications 10.2(2019):454-458.

[2] Zeithaml, Valarie A. "Consumer Perceptions of Price, Quality, and Value: A Means-End Model and Synthesis of Evidence." Journal of Marketing 52.3(1988): 2-22.

[3] Childers, Terry L., et al. "Hedonic and utilitarian motivations for online retail shopping behavior." 77.4(2001):511-535.

[4] Ecommerce Customers https://www.kaggle.com/srolka/ecommercecustomers

[5] $\mathrm{He}, \mathrm{Wu}$, et al. "Application of social media analytics: a case of analyzing online hotel reviews." Online Information Review 41.7(2017):921-935.

[6] Amazon Customer Reviews.

https://www.kaggle.com/vandan2223/amazoncustomer-reviews

[7] Luo Huihui, Liu Xiantao, Wu Yi. The collision between technological innovation and market: a case study of iridium project and PHS [J]. Research on technological economy and management, 2005 (1): 64-65. 